\title{
NON-INVASIVE APPROACHES FOR LOW-ENERGY RETROFIT OF BUILDINGS: IMPLEMENTATION, MONITORING AND SIMULATION IN A LIVING LAB CASE STUDY
}

\author{
MONICA MATEO-GARCIA, ABDULLAHI AHMED \& DANNY MCGOUGH \\ Coventry University, UK
}

\begin{abstract}
There is urgent need for Europe to transform into a low-carbon economy to reduce the risk of climate change. The building sector is responsible for nearly $40 \%$ of the total energy consumption in Europe. In order to achieve substantial energy and greenhouse gas (GHG) emission reductions, low-energy retrofitting of existing buildings becomes a very important challenge/opportunity in both domestic and non-domestic buildings. A considerable number of existing buildings are either protected or contain hazardous materials limiting the potential for conventional retrofitting approaches for improving the existing façades. Retrofitting Solutions and Services for the enhancement of Energy Efficiency in Public Buildings (RESSEEPE) is an EU-funded research project that focuses on the refurbishment of existing public buildings in different European cities. A case study approach is used to implement and monitor the performance of a range of building fabric materials. The case study focuses on a demo building in Coventry University, located within the city centre of Coventry. The paper documents the materials selection and the low-carbon refurbishment, monitoring and simulation process followed. As asbestos was found in the building, it was necessary to ensure that the materials and technologies selected didn't interfere with the existing elements of the façade. The materials finally installed were specifically selected to work as an addition of layers rather than substitution of elements. The living lab nature of the demo-site aims to set an example for low carbon refurbishment in protected or existing buildings with hazardous materials, with a non-invasive approach based on state-of-the-art materials and technologies.
\end{abstract}

Keywords: existing buildings, energy performance, non-destructive testing, building performance diagnostics, innovative materials, passive design.

\section{INTRODUCTION}

Buildings account for $40 \%$ of total energy consumption in the EU and generate $36 \%$ of the greenhouse gases in Europe [1]. The construction sector is on its critical path to decarbonise the European economy by 2050 , reducing its $\mathrm{CO}_{2}$ emissions by at least $80 \%$ and its energy consumption by as much as $50 \%$. As the replacement rate of the existing stock is very small (1-2\% per year), one of the most cost-effective measures to meet energy reduction targets is to address the existing building stock across Europe, which offers one of the most significant challenge for meeting the energy and environmental targets [2]. Annually new non-domestic buildings represent less than 1.5 percent of the total building stock across, therefore the improvement and management of existing non-domestic buildings offer significant potential for achieving energy and environmental savings compared to the construction of new buildings [3].

Retrofitting Solutions and Services for the enhancement of Energy Efficiency in Public Buildings (RESSEEPE) is an EU funded project which aims to develop and demonstrate a replicable methodology for designing, constructing, and managing public buildings and district renovation projects to achieve a target of $50 \%$ energy reduction. For this purpose, a demonstration and dissemination framework is developed based on the following pillars: cost-effective solutions for holistic energy performance improvement at building and district 
levels; systemic selection process to achieve optimal mix of intervention measures from a wide range of innovative technologies; market and replication deployment plan and exploitation strategy suitable for achieving a wide impact.

RESSEEPE project focuses on the refurbishment of existing public buildings in three European cities representative of the breadth of EU climate conditions: Coventry (UK), Barcelona (Spain) and Skelleftea (Sweden). Coventry University contributes to the project with two buildings: Sir John Laing (JL) and Richard Crossman (RC) Buildings. This paper focuses on Sir John Laing's case study, used as a Testing Bed for innovative technologies new to the market and developed specifically within the project framework.

\section{CASE STUDY DESCRIPTION}

Coventry University is a large contributor to the city's economy. The university and the council own about $90 \%$ of the built asset within the city centre. The planning approach for the city moving forward is the recognition of a living lab status, "establishing Coventry as a test-bed, incubation hub and international showcase for low carbon innovations" [4]. The living lab status holds high relevance to this project, as the case study building encompass a living lab ethos acting as a live experimental facility for a number of innovative technologies.

The case study building is typical of the range of buildings owned by Coventry University and Coventry City Council. The majority of these buildings were constructed between the 1930s and 1970s, when the building energy efficiency level was very poor (the first Energy Efficiency component of the UK building regulation was developed in 1985 [5]). Because of the age of the buildings, the energy performance of most of the building stock is also very poor. The selected case study building is a typical 1970s building made of brick and single glazing. Although the building is close to the end of its life, if embodied and operational energy were accounted for, the case for refurbishment was strong.

As stated by the Association of University Directors of Estate (AUDE), many universities own a considerable number of 1960s and 1970s buildings and, as a result of this, are facing a problem of building stock that is progressively becoming out of date and unfit for purpose [6]. The hard choice owners of these type of buildings are facing is whether to retrofit them to achieve the standard performance expected of a 21 st century building or carry out a full demolition and rebuild. AUDE identified a number of relevant key points:

- Academic buildings can often be refurbished more successfully than residential;

- While the financial case for refurbishment might look poor, with costs in some cases as high as $80 \%$ of a new build option, there are often significant environmental benefits from refurbishment. High standards of environmental performance can be achieved on refurbishment projects, provided that the objective is at the core of the design from the outset;

- Architectural excellence can still be achieved in refurbishment projects.

The case study building has two storeys. The façade is a brick masonry cavity wall with a $30 \%$ glazed proportion. The windows have metal frames with a 6-mm single glazing (Fig. 1). The structure is a concrete frame system.

\section{METHODOLOGY}

The case study at Coventry aims to retrofit some areas of the building in order to extrapolate the results to the whole building and evaluate the overall potential savings after refurbishment. This is expected to provide enough data and perspective to enable extrapolation to wider urban retrofit of existing buildings. 

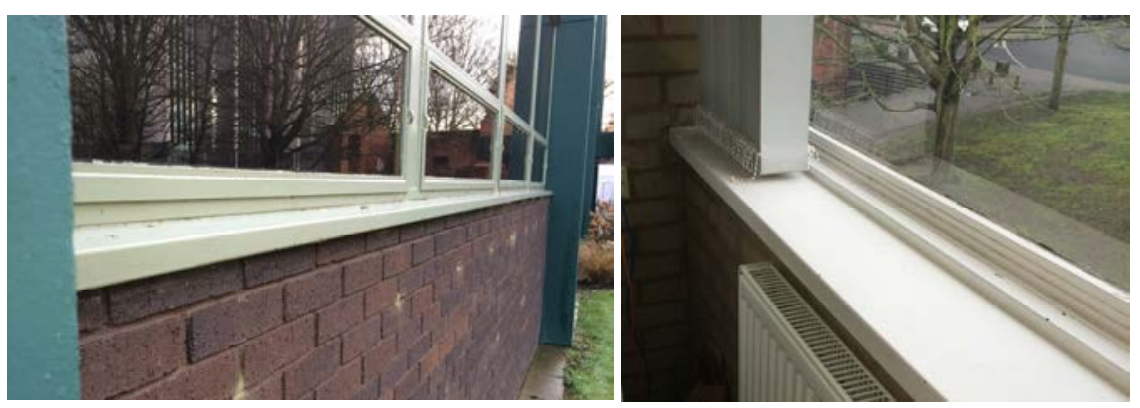

Figure 1: Case study brick wall and window detail.

The building performance evaluation protocol developed covers the pre- and post-retrofit evaluation of the building and the performance of the technologies selected and implemented. The aim of the building performance evaluation is to assess three key factors, namely building and system characteristics, environmental factors and occupant perception [7]. These performance evaluation protocols are applied at different stages of the project: building selection stage, pre-retrofit or feasibility studies stage, installation and post installation stages. The purpose of the building performance evaluation strategy is:

- To monitor the objective measures of comfort within buildings (temperature, humidity, $\mathrm{CO}_{2}$ ) before and after retrofit;

- To investigate building fabric performance;

- To evaluate user perception;

- To evaluate the installation process;

- To model the performance of the building (pre- and post-retrofit).

Therefore, the methodology followed includes: experimental monitoring, modelling, benchmarking of energy and environmental performance and surveys to key stakeholders and people involved in the installation process.

\subsection{Existing building fabric performance assessment}

In new buildings we are able to define and track all the constructive details and composition of the building envelope with a high level of accuracy. However, when approaching the refurbishment of existing buildings, especially in old buildings, we face some problems such as lack of technical documents and non-documented retrofits which lead to unawareness of the composition of the roof, glazing and building fabric. Due to these factors, it is difficult to predict with accuracy the actual energy performance of the existing building. This consideration is even higher when dealing with listed buildings, which may not be demolished, extended, or altered without special permission from the local planning authority, particularly for significant alterations to the more notable listed buildings.

To minimize this challenge, a range of building performance evaluation protocols has been used to evaluate the performance of the existing building fabric before selection of technologies. Key performance criteria included:

- Analysis of the existing constructive documents of the building in order to get the maximum information of the composition of the external walls.

- Building fabric performance assessment by non-destructive testing. 
- Infrared thermography surveys.

- U-value of the existing wall (heat flux sensors).

- Indoor Environmental Quality measurements (temperature, humidity, $\mathrm{CO}_{2}$ ).

- Asbestos survey.

- User comfort analysis.

In order to determine the composition of the existing envelope, technical documents obtained from the archives of the Estates Department were analysed. As the information available was incomplete, feedback was also sought from staff from the Estates Department and technicians from the case study building. The main aim was to gather not only information about the original composition, but also about the different retrofits and alterations that the building might have experienced during its life time.

Also, due to the suspicion that there was asbestos within the building, as it was constructed in 1970, an asbestos survey had to be conducted before any retrofitting works. This survey would give us valuable data about the possible existence of hazardous materials in the building envelope before selecting the technologies to be finally installed.

\subsection{Evaluation of user perception}

A refurbishment project can achieve a greater user satisfaction. One opportunity that the refurbishment of an existing building offers is that we are able to have a better knowledge of the occupant patterns of use of the existing building before the refurbishment process starts. For the evaluation of user perception and comfort assessment, user satisfaction surveys have been planned to be distributed before and after the retrofitting activities among the users of the building. This will provide a range of data set to compare the user satisfaction pre- and post-interventions.

Furthermore, stakeholder engagement events are being organized periodically to gather feedback from end users, Estates Department, Facility Managers, public bodies, industry, etc. Interviews will also be done with the stakeholders in the installation process: technology providers, contractors, etc. Their views in conjunction with researcher assessment of the installation process will provide data from which evaluations and lessons learnt from the process can be extracted. Fig. 2 summarises the strategy for the evaluation of social acceptance.
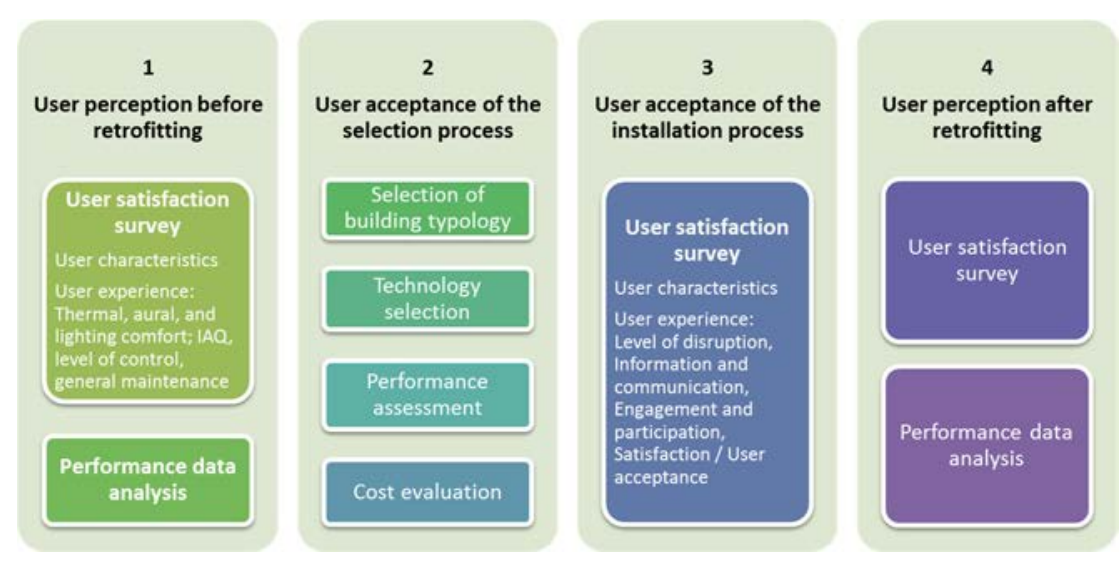

Figure 2: Evaluation of social acceptance. 


\section{TECHNOLOGY SELECTION}

In order to select the best possible mix of technologies, Coventry University made analytical evaluations of the feasibility of different innovative materials to assess initial potential. A decision-making criteria was followed to evaluate suitability of technologies for specific location, building energy and environmental performance as well as building use condition. The decision-making criteria also included the whole life cycle cost and environmental life cycle of the components system.

Coventry University demo-site developed a strategy for implementation and testing of these technologies. This strategy consisted of designing and implementing a selection of innovative technologies in specific areas of an existing building. This gave the project an opportunity to test these technologies in a real environment while at the same time limiting the risk exposure for the university. The state of art technologies selected after the decisionmaking criteria evaluation are categorised into three groups: envelope, building services, and renewable technologies (Fig. 3).

The decision-making criteria analysis was completed with a building performance assessment of the existing fabric using non-destructive testing, including an analysis of the existing constructive documents of the building, infrared thermography survey, asbestos survey, indoor environmental quality measurements and user comfort analysis.

In the Asbestos Survey, small quantities of asbestos-containing materials were found. In particular, asbestos packing within fixing holes to concrete around windows as shown in (Fig. 4). Although the façade and envelope in the case study building had potential for alteration due to a current non-structural façade and accessible load bearing capable frame, the technology selection and installation had to be reconsidered after finding the asbestos.

As any proposed demolition/redevelopment works were liable to result in damage and disturbance to the identified material, it was necessary to ensure that the materials and technologies selected didn't interfere with the existing elements of the façade. As a result of this, the materials and technologies finally selected were specifically chosen for their capacity to work as an addition of layers rather than substitution of elements. This situation meant not being able to change the single glazed units to high efficiency glazing as originally planned and also reconsidering the fixing details of the other technologies.
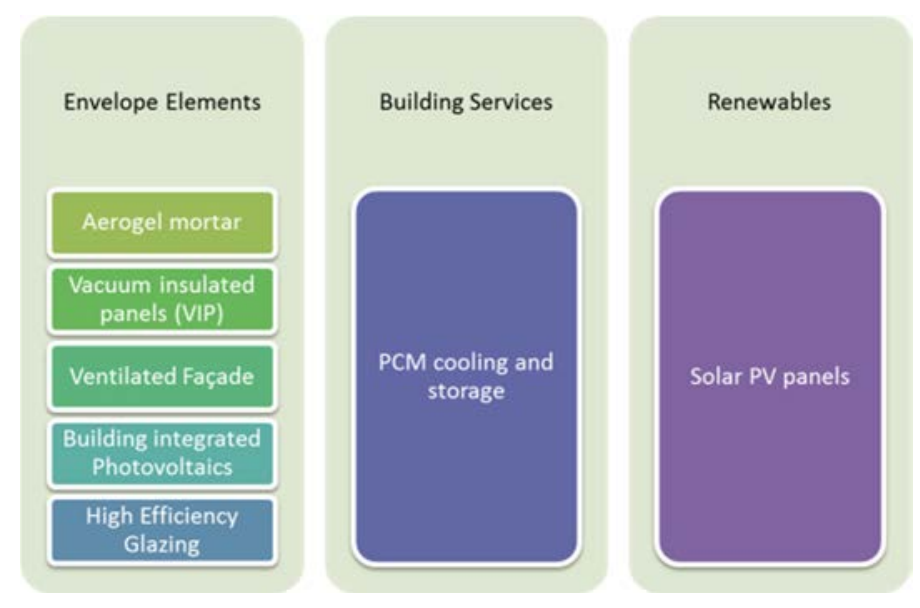

Figure 3: Technologies finally selected for case study building. 

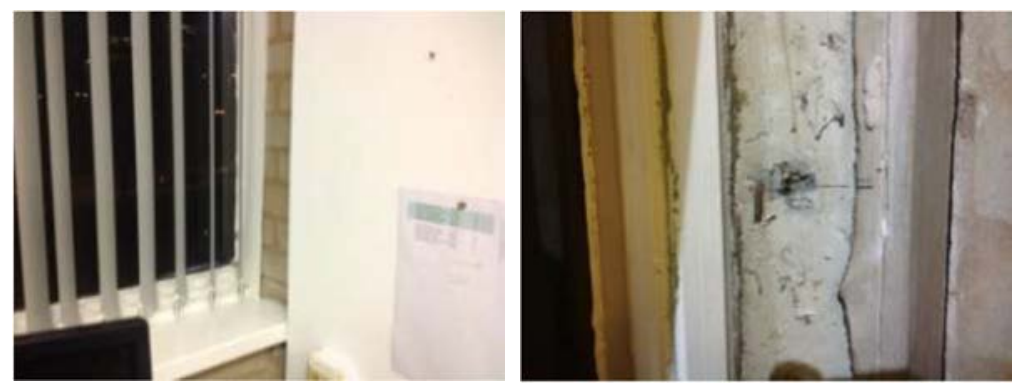

Figure 4: Detail of the loose insulation containing asbestos around screw holes found.

To complete the building performance assessment before final selection of technologies and implementation, a user comfort survey was distributed between end-users of the building (students and staff). After the data collection and analysis some interesting results were found.

As shown in Fig. 5, students found classrooms uncomfortable both during the winter and summer. This is caused by overheating of these spaces because they have high internal gains due to high student numbers over long hours during day and night, density of computers and other heat emitting equipment. Also, during the winter months, users often report cold temperatures especially in the mornings.

For staff, poor thermal comfort was detected especially in the summer (Fig. 6). This is because most of the offices are facing west and have poor ventilation conditions.
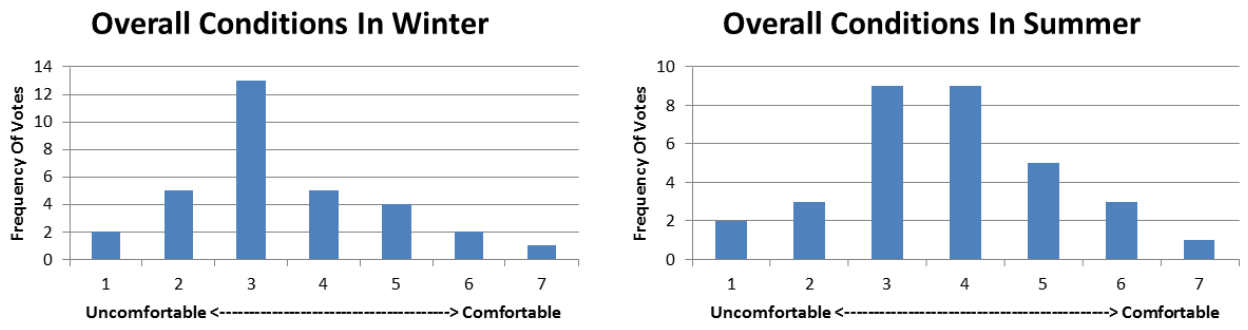

Figure 5: Overall conditions in winter and summer for student classrooms.
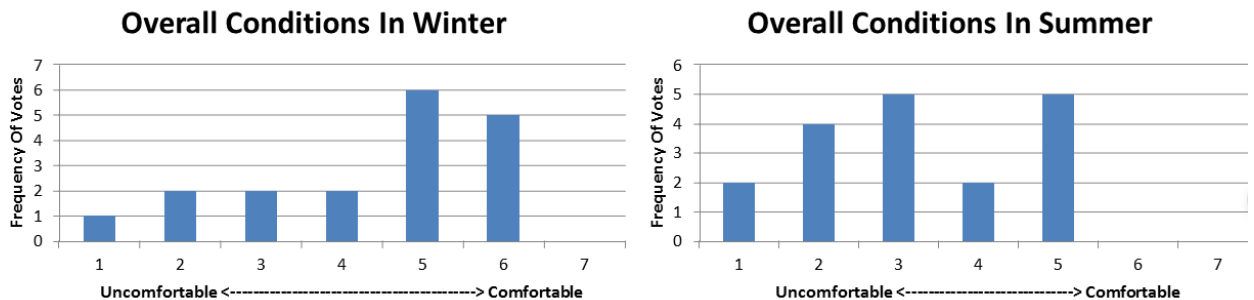

Figure 6: Overall conditions in winter and summer for office rooms. 
After the decision-making criteria process and the building performance assessment of the existing fabric, the list of state-of-the-art technologies finally selected is as follows (see Table 1).

Table 1: Summary of technology development.

\begin{tabular}{|c|c|}
\hline Technology & Description of technology \\
\hline Aerogel-based mortar & $\begin{array}{l}\text { It consists of a very porous ultra-light material that combines aerogel with cement } \\
\text { to provide super-insulating properties. Due to its low density and small pores this } \\
\text { material shows a remarkably low thermal conductivity }(\lambda) \text {, in accordance with } \\
\text { literature reported values }(\boldsymbol{\lambda} \mathbf{0 . 0 2 0} \mathbf{W} / \mathbf{m K}) \text {. This property makes this product } \\
\text { highly interesting for insulating applications in construction. } \\
\text { This is an innovative application of aerogel as rendering because although there } \\
\text { are examples of insulating renderings using aerogel aggregates, they are not based } \\
\text { in cement materials and their application is for inside building walls [8]. } \\
\text { Non-invasive approach: The material is applied just as an exterior render with } \\
\text { high insulating properties, avoiding any interference with the existing elements } \\
\text { of the façade. }\end{array}$ \\
\hline $\begin{array}{l}\text { Ventilated façade with } \\
\text { photovoltaic panels }\end{array}$ & $\begin{array}{l}\text { Among the emergent advanced façades, double-skin façades (DSFs) are an } \\
\text { efficient solution to control the interactions of indoor and outdoor environments } \\
\text { [9]. Double skin façades can efficiently reduce the overall HVAC consumption } \\
\text { in buildings by absorbing part of the solar radiation during winter and preventing } \\
\text { overheating during warm periods [10]. The ventilated façade proposed for the } \\
\text { project has a photovoltaic system (PV) as an outer layer. The different parts that } \\
\text { compose the ventilated facade are: insulation layer of Vacuum Insulated Panels } \\
\text { (VIP), steel substructure and photovoltaic modules fixed with aluminium clamps. } \\
\text { Non-invasive approach: All the anchors used for the ventilated façade have been } \\
\text { fixed into the concrete columns, reducing the number of anchors needed and } \\
\text { avoiding any fixings in the brick wall. }\end{array}$ \\
\hline $\begin{array}{l}\text { Vacuum-insulated panels } \\
\text { (VIP) }\end{array}$ & $\begin{array}{l}\text { VIP can be described as 'evacuated open porous materials inside a multi-layered } \\
\text { envelope'. They are considered to be one of the most effective insulation } \\
\text { materials available. VIPs consist of three components: the core, the envelope and } \\
\text { getters (a reactive material to help maintain the vacuum, e.g. desiccants and } \\
\text { opacifiers). The core of the plate is evacuated and determines the thickness of the } \\
\text { plate. A foil envelope keeps the vacuum inside and avoids gas and moisture } \\
\text { permeation into the core as long as possible [11]. } \\
\text { Non-invasive approach: The material is applied just as an External Thermal } \\
\text { Insulation Composite System (ETICS), avoiding any interference with the } \\
\text { existing elements of the façade. }\end{array}$ \\
\hline $\begin{array}{l}\text { PCM energy storage } \\
\text { tubes (PCM) }\end{array}$ & $\begin{array}{l}\text { PCM: The thermal storage capacity of a material is a measure of a material ability } \\
\text { to absorb and store thermal energy and subsequently release it back to the } \\
\text { environment after a period of time. There are two broad types of thermal storage } \\
\text { materials, namely sensible and latent heat storage materials. Sensible heat storage } \\
\text { materials include brick, concrete, rocks etc. The sensible thermal storage of these } \\
\text { materials is as a result of the change in temperature of the materials. PCMs are } \\
\text { material compounds that melt or solidify at certain temperatures to store or release } \\
\text { large amounts of energy [12]. } \\
\text { Non-invasive approach: After guaranteeing the absence of asbestos in the } \\
\text { ceiling and the structural integrity, the PCM tubes were fixed using a standard } \\
\text { tube fixing bracket system, which was fixed to the underside of the ceiling. }\end{array}$ \\
\hline High-efficiency glazing & $\begin{array}{l}\text { Non-invasive approach: This technology had to be reconsidered after finding } \\
\text { asbestos around windows. In order not to touch the windows, it was decided to } \\
\text { install a second glazing layer on the inside, just fixed into the brick partition walls. } \\
\text { Also, to avoid excessive glare, switchable films were selected. }\end{array}$ \\
\hline
\end{tabular}




\section{INSTALLATION PROCESS AND USER ACCEPTANCE}

\subsection{Installation process}

The first major works at the case study building consisted of the installation of Phase Change Materials (PCM), ventilated façade with vacuum insulated and solar panels, and exterior insulation with EPS and aerogel mortar. Fig. 7 shows the location of the various technologies on the building façade and internal spaces. The installation process was managed by the technical coordinators and the technology providers from RESSEEPE project with support from Coventry University.

PCM was selected for use in the architectural studio space (JL121/122) to counteract overheating because the space is occupied by high student numbers over long hours during day and night and has high internal gains due to density of computers and other heat emitting equipment. The space is naturally ventilated providing the ideal environment for testing a passive solution. Also, to investigate different space use and control mechanisms, PCM was installed in two small office spaces (less than $20 \mathrm{~m}^{2}$ ). The selected offices are located on the west façade of the building with high risk of overheating.

VIP insulation has been selected on a west office to counteract the current poorly insulated cavity brick system. The VIP is intended to improve the overall insulation of the space without being invasive of the existing cavity. To further test insulation improvements ETICS with EPS and Aerogel mortar have also been implemented in neighbouring spaces providing a spread to the data experiments. A significant aspect of the interventions is the interaction combination space of JL137, which has been impacted by PCM and Ventilated façade (VIP and BIPV). This provides a critical zone where the interconnection of technologies can be analysed.

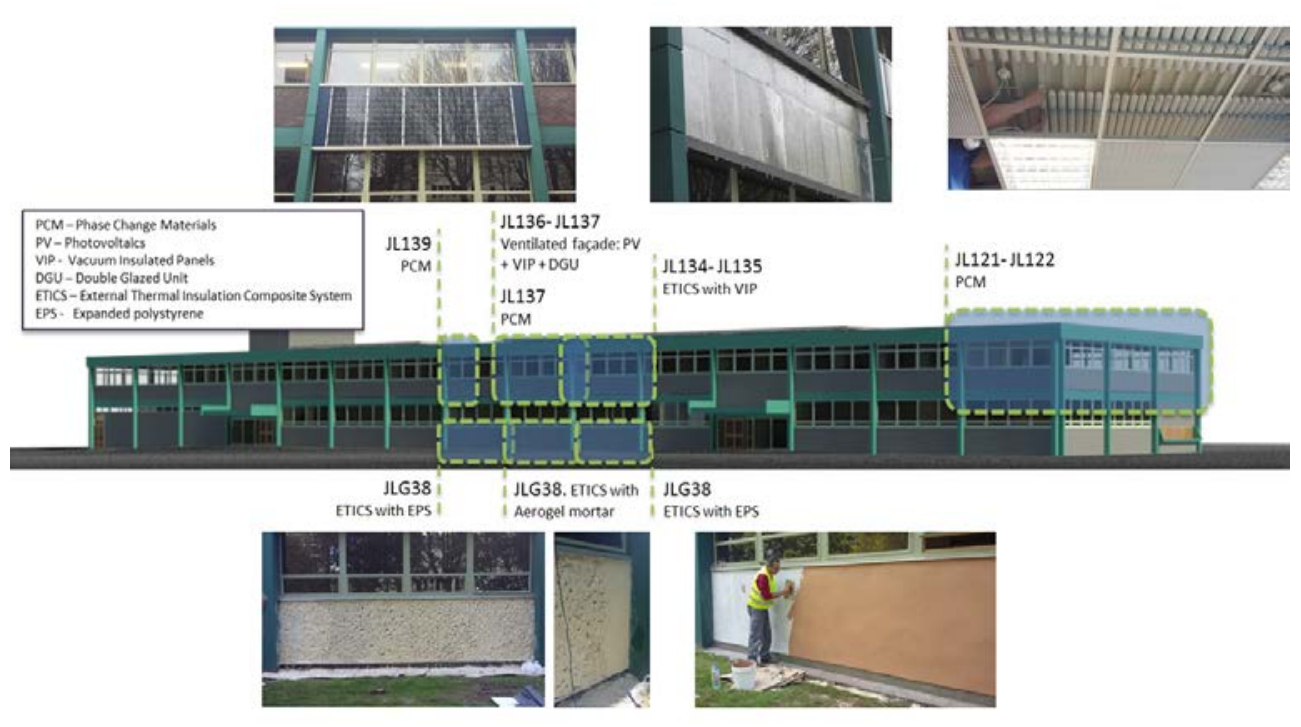

Figure 7: Location of the interventions in the case study. 
One of the challenges with installation was the novelty of some of the technologies. In the case of PCM installation, a number of local contractors were approached to install but were put off by the increased risk of dealing with a new technology. Prior to installation there were concerns over the integrity of the tubes and the risk of leakage of the PCM. Certain protocols had to be adhered to, such as a structural assessment of the space and an asbestos survey, both to ensure that firstly the structure could hold the increased loading of the PCM tubes and secondly to ensure that there is no risk of exposure to asbestos by both installers and users of the building. The PCM tubes were fixed using a standard tube fixing bracket system, which was fixed to the underside of the ceiling.

The ventilated facade was conceived and manufactured within the RESSEEPE project. The partners involved in the manufacturing of the structure and the assemblies of the system were from a different country, which implied a carefully designed installation process and the validation of the system beforehand.

The aerogel mortar was tested and manufactured specifically for its application in Coventry University. Due to its innovative nature, a theoretical and practical training was done by the manufacturer in order to ensure a good product application. The application of the aerogel mortar was done by hand instead of the spray system, this implied having to test different percentages of water-mortar ratio in order to achieve a good performance.

\subsection{User acceptance}

After the installation of the different innovative materials and technologies several stakeholder engagement events will be held to gather feedback about the installation process, architectural integration of the technologies and user comfort after retrofit.

The assessment of the user acceptance is vital for guaranteeing the acceptance of the technologies implemented, with a special focus on the architectural integration of the technologies. This reasoning is behind the installation of the same constructive solution (ETICS with EPS) in different panels but with different finishes, in order to gather feedback from different stakeholders about the solutions.

\section{MONITORING AND SIMULATION}

Non-invasive monitoring techniques help us get a better understanding of the real energy performance of an existing building without the use of invasive methods. The monitoring equipment used in the case study building is the following (Fig. 8):

- $\quad$ FLIR Thermal Imaging Camera. By using a thermal camera we were able to find discontinuities on the insulation of the exterior wall.

- Heat flux plates: HFP01-Hukseflux thermal sensors.

- Thermocouples: RTD Surface Mount Temperature Sensor, -50 to $150{ }^{\circ} \mathrm{C}, 5 \mathrm{M}$.

- Temperature and RH sensors: Omnisense wireless sensors.

The performance monitoring, such as indoor environmental sensors, heat flux sensors, electricity and gas meters have been installed to monitor individual technologies. The spaces and innovative materials installed will be monitored over the next year to evaluate performance of the system. This evaluation in conjunction with the metering of the energy use of the existing building and the understanding of the occupant behaviour will allow us to make a more accurate energy performance evaluation in order to inform selection of passive building fabric solutions before the refurbishment. 

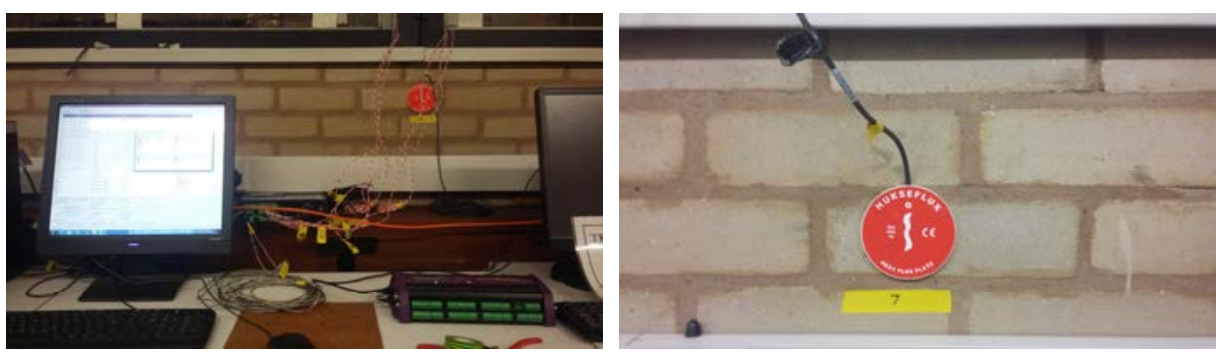

Figure 8: Non-invasive monitoring equipment installed.

Both objective and subjective data will be used to compare rooms with technologies installed to selected controls rooms. Also, data from the monitoring will be used to calibrate the simulation and use it to extrapolate the benefit of these technologies to the entire building. The calibrated models and simulations will also be used to extrapolate results to other buildings within the urban district.

Replicability is a key target of the project. The results obtained after the monitoring process will help determine the suitability of the technologies applied in order to extrapolate the results in the first place to the rest of the building and in the last place to other buildings of a similar typology.

At this stage, it is too early to evaluate energy data in great depth as the in-situ monitoring study is still in its infancy. Additionally, user experiences will be evaluated over the next year before disseminating results. This approach will ensure that performance data is evaluated over summer and winter seasons. A period of 12 months of user experiences and monitoring will provide a robust level of data to establish greater generalisation and ensure higher quality analysis and extrapolation.

\section{CONCLUSION}

The RESEEPEE project aims to achieve energy reduction in the region of 50\% through the use of innovative building fabrics and systems to retrofit public buildings. Coventry University demo-site case study is acting as a Living Lab for testing innovative materials and technologies new to the market and developed within the project. The case study building is typical of the range of buildings constructed between the 1960s and 1980s, characterised by a poor energy performance and the presence of asbestos. This situation led to avoid any interference with the existing elements of the façade. The paper reviews the technology selection, retrofitting process and monitoring of the materials installed using a non-invasive approach, where the technologies and materials work as an addition of layers rather than substitution of elements. The case study described aims to set an example for low carbon refurbishment in protected or existing buildings with hazardous materials, with a non-invasive methodology based on state-of-the-art materials and technologies. The paper also has the potential to make a significant contribution to the strategies for upgrading similar types of buildings owned by universities and other public bodies.

\section{ACKNOWLEDGEMENTS}

This project is funded by the European Union Framework 7 research funding scheme, we would like to acknowledge the contribution of all project partners for their participation and ideas during the development of the project. 


\section{REFERENCES}

[1] Directive 2010/31/EU of the European Parliament and of the Council of 19 May 2010 on the energy performance of buildings.

[2] Baker, N.V., The Handbook of Sustainable Refurbishment: Non-Domestic Buildings, Earthscan co-published with RIBA Publishing: London, pp. 3-4, 2009.

[3] Energy-Efficient Buildings. Multi-annual Roadmap for contractual PPP under Horizon 2020, European Commission Directorate-General for Research \& Innovation: Brussels, Belgium, pp. 6-7, 2013.

[4] City Lab Coventry, www.openlivinglabs.eu/livinglab/city-lab-coventry

[5] Building Regulations 1985 (SI 1985/1066), UK, www.legislation.gov.uk/uksi/1985/ 1065/pdfs/uksi_19851065_en.pdf

[6] The Legacy of 1960s University Buildings, AUDE 2008, www.aude.ac.uk

[7] ASHRAE, Performance Measurement Protocol for Commercial Buildings, ASHRAE: Atlanta, GA, 2010.

[8] Stahl, T., Brunner, S., Zimmermann, M. \& Ghazi Wakili, K., Thermo-hygric properties of a newly developed aerogel based insulation rendering for both exterior and interior applications. Energy and Buildings, 44, pp. 114-117, 2012.

[9] Ghaffarianhoseini, A., Berardi, U., Tookey, J., Li, D.H.W. \& Kariminia, S., Exploring the advantages and challenges of double-skin façades (DSFs). Renewable and Sustainable Energy Reviews, 60, pp. 1052-1065, 2016.

[10] Barbosa, S. \& Ip, K., Perspectives of double skin façades for naturally ventilated buildings: A review. Renewable and Sustainable Energy Reviews, 40, pp. 1019-1029, 2014.

[11] Livesey, K., Suttie, E., Scovell, K. \& Thielmans, W., Advanced thermal insulation technologies in the built environment, n.d.

[12] Iten, M. \& Liu, S., A work procedure of utilising PCMs as thermal storage systems based on air-TES systems. Energy Conversion and Management, 77, pp. 608-627, 2014. 